\title{
HETEROGENEITY OF TRITERPENES AND STEROIDS STRUCTURE AS DPP-4 INHIBITORS: A REVIEW ARTICLE
}

\author{
K. Budipramana ${ }^{1,2, \bowtie}$, K.R. Wirasutisna ${ }^{1}$, M.W. Wartono ${ }^{3}$, Y.B. Pramana ${ }^{4}$, \\ S. Sukrasno ${ }^{1,5}$ and T.A. Yuniarta ${ }^{6}$ \\ ${ }^{1}$ Pharmaceutical Biology Research Group, School of Pharmacy, Bandung Institute of \\ Technology, Bandung-40132, Indonesia \\ ${ }^{2}$ Department of Pharmaceutical Biology, Faculty of Pharmacy, University of Surabaya, \\ Surabaya-60293, Indonesia \\ ${ }^{3}$ Chemistry Department Faculty of Mathematics and Natural Sciences Sebelas Maret \\ University, Surakarta-57126, Indonesia \\ ${ }^{4}$ Industrial Engineering Department, Faculty of Industrial Technology, University of PGRI \\ Adi Buana Surabaya-60234, Indonesia \\ ${ }^{5}$ Department of Pharmacy, Sumatera Institute of Technology, South Lampung-35365, \\ Sumatera, Indonesia \\ ${ }^{6}$ Department of Pharmaceutical Chemistry, Faculty of Pharmacy, University of Surabaya, \\ Jalan Raya Kali Rungkut, Surabaya \\ ${ }^{\circledR}$ Corresponding Author: krisyantibudipramana@staff.ubaya.ac.id
}

\begin{abstract}
Dipeptidyl peptidase-4 (DPP-4) inhibitors are diabetes mellitus drugs that inhibit the metabolism of glucagonlike peptide-1 (GLP-1) from the DPP-4 enzyme thus prolong the half-life of GLP-1. This review provides an overview of DPP-4 inhibitors from triterpenes and steroids and some related compounds from in silico prediction, in vitro, and in vivo studies. The knowledge of the heterogeneity of DPP-4 inhibitors structure from synthetic drugs as well as natural sources will assist to design more potential DPP-4 inhibitors, yet it is needed to be evaluated clinically. Hopefully, the scientific combination among molecular modelling and experimental studies perspectives will generate DPP-4 inhibitors with the desired outcome.
\end{abstract}

Keywords: Diabetes mellitus, DPP-4 Inhibitor, In-silico, In-vitro, Triterpenes, Steroids.

RASĀYAN J. Chem., Vol. 14, No.1, 2021

\section{INTRODUCTION}

Diabetes mellitus (DM) is a chronic disease associated with metabolic disorder syndrome in carbohydrate, protein, and fat1. Diabetes mellitus type 2 is more predominant than diabetes mellitus type 1. In 2014, about 422 million people diagnosed with DM and this prevalence increased almost four times compared to 19802. In 2040, the International Diabetes Federation estimates that 642 million people will live with $\mathrm{DM}^{3}$. Diabetes mellitus might affect all ages and all countries. The youngest child in the world to be diagnosed with DM type 2 is 3 year old4. The prevalence of DM in developing countries also increases faster than in developed countries.

$\mathrm{DM}$ is a chronic disease that can induce microvascular and macrovascular complications. Microvascular complications including neuropathy, nephropathy, and retinopathy whilst macrovascular complications such as a coronary artery, peripheral artery, disease, and stroke. The primary goal of diabetes mellitus therapy is the combination of changing the lifestyle and medicines treatment to reduce the manifestation of more serious complications, decrease mortality, and increase the quality of life5,6. Current medicines to treat diabetes mellitus such as sulfonylureas and thiazolidinediones tend to induce hypoglycemia and weight gain5. As maintaining body weight is one of the diabetes mellitus goal therapy, a new medicine which does not induce weight gain is needed.

A relatively new diabetes mellitus therapy, DPP-4 inhibitors, was firstly released in October 2006 based on its pathophysiology. The discovery of the DPP-4 inhibitor was initiated in the early 1900s where the administration of oral glucose produces higher incretin hormone than via intravenous route, indicating glucose stimulation on $\beta$ cell pancreas. The incretin, intestinal secretion insulin, consisted 
of two predominant hormones, glucose-dependent insulinotropic (GIP) and GLP-1. The concentration of GIP hormone in diabetic patient type 2 is common, has minimal effect on glucagon suppression, and does not enhance insulin secretion. On the contrary, GLP-1 hormone has low concentration, decreases glucagon release, and sensitive to stimulate insulin. However, the limitation of the GLP-1 hormone is its short half-life of around two minutes due to the degradation by an enzyme called DPP4. By blocking the DPP-4 enzyme, it can maximize the potential of GLP-1 to stimulate insulin thus reduce postprandial blood glucose 7-9. Therefore, DPP-4 inhibitors are being developed and pursued. Moreover, treatment of DPP-4 inhibitors as single therapy or combination is reported weight neutrality in DM type 2 patients 10.

The popularity of ethnomedicine to prevent or cure diseases has been known widely due to low toxic effects and minimum cost than modern medicines11. By 2018, the trending market for herbals supplements has been increased 9.4\% from 2017 in the United States. In 2018, people spent 8.8 billion USD in total for supplement, while the demand for triterpenes and steroids are estimated around 12.4 billion USD yearly ${ }^{12-} 13$. Since the use of traditional plants especially triterpenes, steroids, and some related compounds show promising efficacy, this review presents triterpenes steroids and related structures of DPP-4 inhibitors.

\section{Structure of DPP-4 Inhibitors by In-silico}

\section{EXPERIMENTAL}

\section{Binding Site according to Cyanopyrrolidine Structure}

The structure of DPP-4 inhibitors are heterogeneous and summarized in Fig.-1. Marvaniya and Patel14 proposed that there were two requirements for cyanopyrrolidines to interact with the DPP-4 enzyme. First, it was suggested that the inhibitors of DPP-4 have nitrile in the scissile bond. A bond which can be cleaved by enzyme is called the scissile bond.

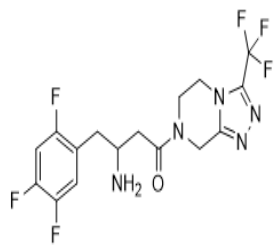

Sitagliptin<smiles>Cn1c(=O)cc(N2CCCCC2N)n(Cc2ccccc2C#N)c1=O</smiles>

Alogliptin

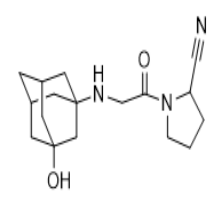

Vildagliptin

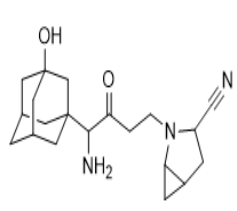

Saxagliptin

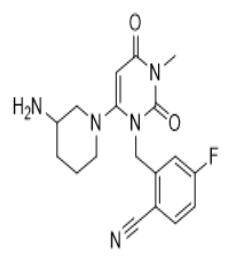

Trelagliptin
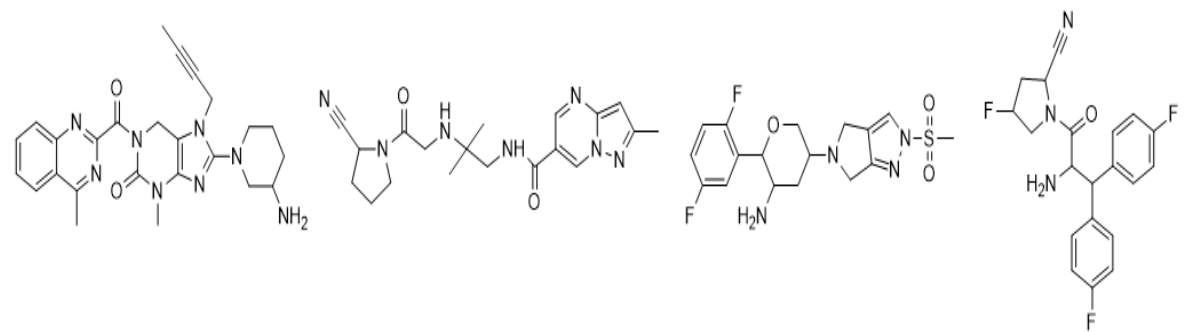

Denagliptin

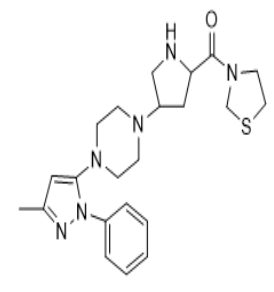

Tenegliptin

Fig.-1:Heterogeneity of DPP-4 inhibitors Structure

The nitrile in the scissile bond will bind with serine (Ser630) in the catalytic site of the receptor to form a covalent bond and act as competitive inhibitors. Second, hydrogen bonding between protonated inhibitor compounds and the negative charge of the surface receptor. Three amino acid residues in the region which are negatively charged are Glu205, Glu206, and Tyr662. The removal of amine group will decrease the potency common protonated region from DPP-4 inhibitors is amine. Nevertheless, the removal of amine group will decrease the potency. Sitagliptin, alogliptin, linagliptin, and tenegliptin make salt bridges with Glu205 and Glu20616.

Substitution of methylsulfonamide analog in omarigliptin led this drug to have the longest half-life among other DPP-4 inhibitors and it only takes once a week dosing17. Also, Arulmozhiraja et al14 proposed that Trp629 and Tyr547 amino acids are important in S2' pocket (Table-1) and interaction with Tyr666 and Phe357 are significant to make hydrophobic bond. Lai et al18 investigated that the potency of linagliptin is higher than alogliptin due to interaction with Trp629 and Tyr547. 
RASĀYAN J. Chem.

Vol. 14 | No. 1 |149-154| January - March | 2021

Table-1: Amino Acid Residues of DPP-4 Pocket

\begin{tabular}{|c|c|c|c|c|c|c|c|c|c|c|}
\hline Pocket & \multicolumn{7}{|c|}{ Amino Acids Residues } & \multicolumn{3}{|c|}{ Inhibitor Class of DPP-4 } \\
\hline S2 ext & Phe357 & Arg358 & Ser209 & Val207 & & & & & & \\
\hline $\mathrm{S} 1$ & Tyr666 & Ser630 & Val656 & Trp659 & Tyr662 & Val711 & $\operatorname{Asn} 710$ & $\mathrm{I}$ & II & \\
\hline $\mathrm{S} 2$ & Arg125 & Arg669 & Glu205 & Glu206 & Phe357 & Arg358 & & $\begin{array}{l}\text { Vildagliptin } \\
\text { Sxagliptin }\end{array}$ & $\begin{array}{l}\text { Alogliptin } \\
\text { Linagliptin }\end{array}$ & $\begin{array}{l}\text { Sitagliptin } \\
\text { Tenegliptin }\end{array}$ \\
\hline S1' & Tyr547 & Tyr631 & Phe357 & Pro550 & Tyr666 & & & & & \\
\hline S2' & Trp629 & His740 & Ser630 & Tyr547 & & & & & & \\
\hline
\end{tabular}

Moreover, DPP-4 inhibitor compounds which can interact with S2 extensively have advantages as their selectivity enhances as well as their potency19. Maladkar and co-workers20 classified DPP-4 inhibitors into 3 classes according to their interaction with DPP-4 pocket (Table-1).

Structure-activity Relationship of Triterpenes and Steroids and Some related Compounds In-silico Geng et al21 examined 12 purified fractions guided as a DPP-4 inhibitor from Inonotus obliquus. This purified fraction contains 19 compounds according to their UPLC-QTOF-MS spectra. As seen in Fig.2 , five compounds $(1,2,5,13$, and 14) were predicted as the active compounds that responsible for DPP-4 inhibitors based on energy binding that almost the same as that sitagliptin as the positive control.

Three compounds $(1,2,5)$ from top five compounds contain amino group with diverse structure and two compounds (13 and 14) were triterpenes and steroid derivates. Compound $1(-113.391 \mathrm{~kJ} / \mathrm{mol})$ and $2(-105.071 \mathrm{~kJ} / \mathrm{mol})$ showed lower binding energy compared to sitagliptin $(-90.2814 \mathrm{~kJ} / \mathrm{mol})$. The lower binding energy means the higher ability of inhibitor compounds to bind the receptor spontaneously to form a more stable interaction22, hence suggests more potential than sitagliptin as DPP-4 inhibitors. From the molecular modelling, compound 1 gives lower binding energy compared to compound 2. Although this result is similar to Marvaniya and Patel14, yet it still needs to be evaluated in vitro, in vivo, or even in clinical studies.
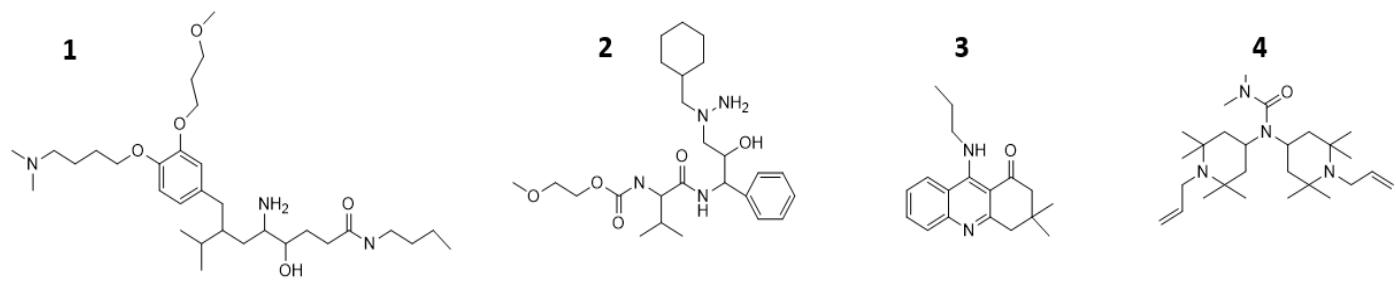

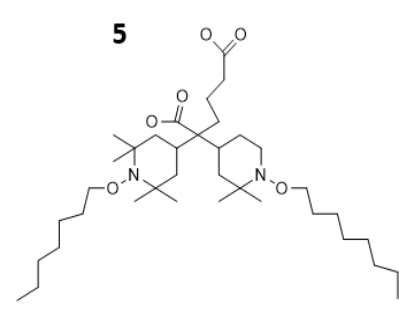

10
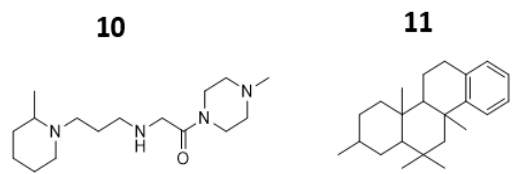

6

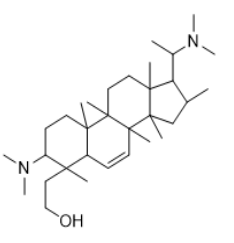

12

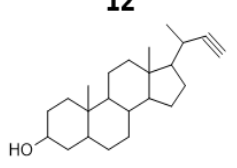

7

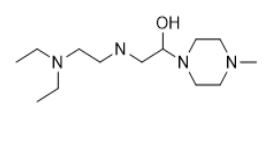

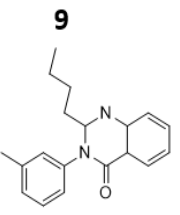
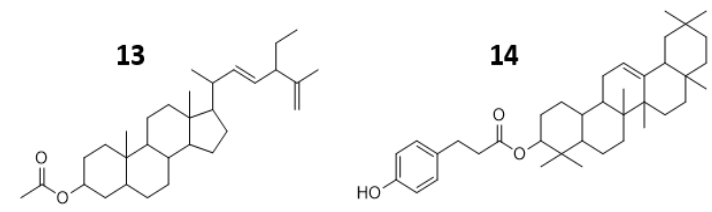

Fig.-2: All the Compounds were obtained from a Fraction guided by DPP-4 Inhibitor

\section{RESULTS AND DISCUSSION}

\section{Structure of DPP-4 Inhibitors by In-vitro and In-vivo Approach}

Terpenoids are composed of isoprene units mostly reported from higher plants. According to the isoprene rule, triterpenoids are categorized from monoterpenoids (C10) to polyterpenoids (> C40)23,24. Due to their widely varied structure terpenoid display various biological activities from to anti-cancer, anti-inflammation, immunomodulators, and anti-diabetic even it can be utilized in cosmetics, food, and perfume23-30.

In Fig.-3, we summarized various triterpenes and steroids reported from some previous studies that had been examined using in vitro and in vivo assay for DPP-4 inhibitor. We compared IC50 of triterpenes or steroids which contain amino groups in their structure31-33. It reveals that triterpenes or steroids as aglycone such as stigmasterol (15), lupeol (16), and quinovic acid (17) have IC50>100; 
31.6; and $30.7 \mu \mathrm{M}$, respectively. In aglycones, their structure differ in the cyclic ring, olefin position, side chains, and the presence of carboxylic acid. Compound (17) has 2 carboxylic acids and gives similar IC50 to that of (16) which has no carboxylic acid. In contrast to (16), stigmasterol (15) give IC50 more than $100 \mu \mathrm{M}$.
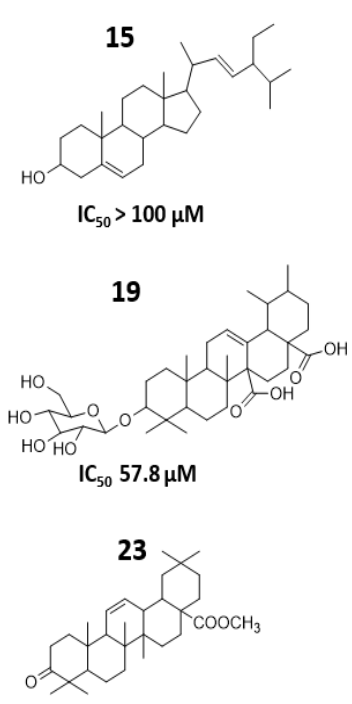

$\mathrm{IC}_{50} 0.091 \mu \mathrm{M}$

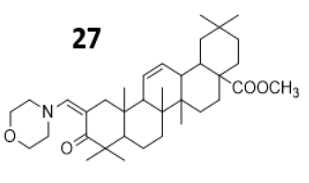

$\mathrm{IC}_{50} 0.062 \mu \mathrm{M}$
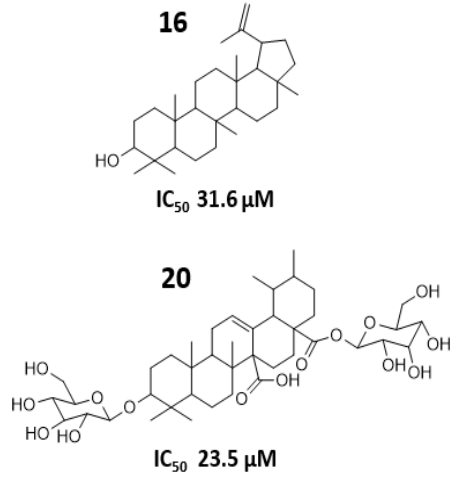

24

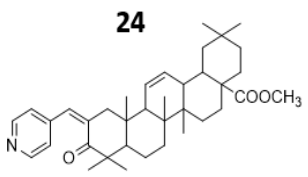

$\mathrm{IC}_{50} 0.033 \mu \mathrm{M}$

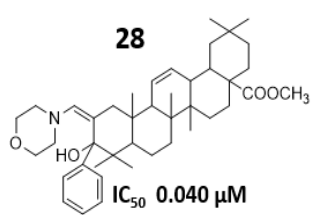

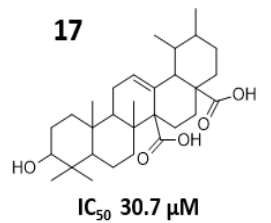
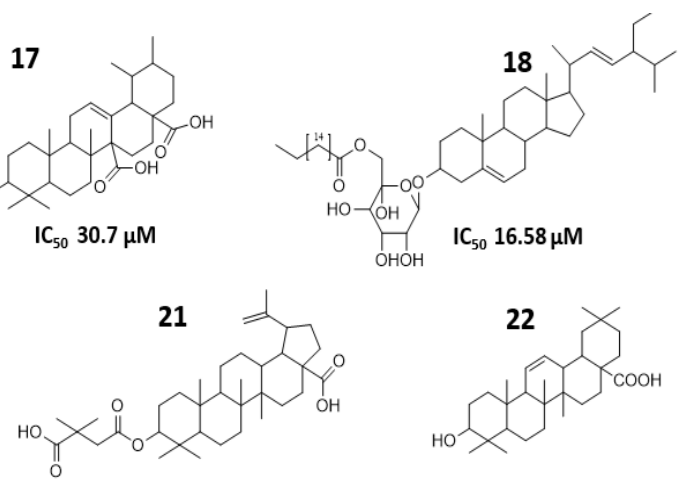

$\mathrm{IC}_{50}-\mu \mathrm{M}$

$\mathrm{IC}_{50} 1.21 \mu \mathrm{M}$

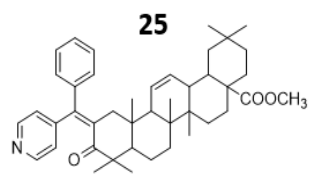

$\mathrm{IC}_{50} 0.022 \mu \mathrm{M}$

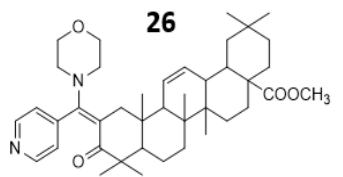

$\mathrm{IC}_{50} 0.0044 \mu \mathrm{M}$

Fig.-3: The Diverse Structure of Triterpenes and Steroids as DPP-4 Inhibitors.

Compound (19) is a glycoside of quinovic acid (17). The addition of 1 glycoside, quinovic acid-3ß-O$\beta$-D-glycopyranoside (19), led to the increase of $\mathrm{IC}_{50}$ to $57.8 \mu \mathrm{M}$ compared to its aglycone. However, the addition of two glycosides in quinovic acid-3 $\beta-O-\beta$-D-glycopyranosyl- $(28 \rightarrow 1)-\beta$-Dglucopyranosyl ester showed IC50 $23.5 \mu \mathrm{M}$. In many reports, triterpenes or steroids glycoside have higher solubility compared to the triterpenes or steroids aglycones. This perhaps due to the addition of glycosyl, hydroxyl, acyl can increase their polarity 23,26 . This profile can also be seen in stigmasterol aglycone (15) and its derivate, 3-O-stigmasterol-(6-O-palmitoyl)-b-D-glucopyranoside (18), that the IC50 of its glycoside from dropped to $16.58 \mu \mathrm{M}$.

Oleanolic acid (22), a pentacyclic triterpene, was reported to have IC50 $1.21 \mu \mathrm{M}$. The methyl esterification of carboxylic acid (23) and oxidation of alcohol into ketone can decrease IC50 to 0.091 $\mu \mathrm{M}$. However, the total modification of 22 into 23 produces a more suitable compound to bind the DPP-4 enzyme. Compounds 22 and 23 also have been examined in diabetic mice to reduce serum glucose34. They also modified oleanolic acid into six derivatives to produce compounds 23-28. Compounds 24-28 contain pyridine ring and/or morpholine ring. The addition of the pyridine ring (24-25) gave lower IC50 values than in addition to the morpholine ring (27-28) while the combination addition of pyridine and morpholine ring gave the lowest IC50 of $0.0044 \mu \mathrm{M}$ (26) to inhibit the DPP4 enzyme. Compound 26 was also claimed effective to inhibit PPAR $\gamma$ enzyme with IC50 0.0078 $\mu \mathrm{M} 34$. In contrast to oleanolic acid, bevirimat (21), was tested using in vitro assay and showed no inhibitory effect on DPP-433.

\section{CONCLUSION}

This finding suggested that the heterogeneity of triterpenes and steroids structure could act as a DPP-4 inhibitor. In finding novel DPP-4 inhibitor compounds, total design and modification predicted inhibitor compounds should be confirmed with in vivo studies and clinical studies.

\section{ACKNOWLEDGMENT}

The publication of this review was sponsored by Indonesia Endowment Fund for Education (LPDP).

\section{REFERENCES}


1. W. Baynes, Journal of Diabetes and Metabolism, 6(5), 541(2015),DOI:10.4172/21556156.1000541

2. World Health Organization, Global Report on Diabetes, 6, (2016).

3. K. Ogurtsova, J.D. da Rocha Fernandes, Y. Huang, U. Linnenkamp, L. Guariguata, N.H. Cho, J.E. Shaw, and L.E. Makaroff, Diabetes Research Clinical Practice, 128, 40(2017), DOI: 10.1016/j.diabres.2017.03.024

4. https://www.medscape.com/viewarticle/851127.

5. A. Chaudhury, D. Chitharajan, S.R.D. Vijaya, S. Kraleti, A. Chada, R. Ravilla, A. Marco, N.S. Shekhawat, M.T. Montales, K. Kuriakose, A. Sasapu, A. Beebe, N. Patil, C.K. Musham, G.P. Lohani, and W. Mirza, Frontiers in Endocrinology, 8(6), 1(2017), DOI: 10.3389/fendo.2017.00006

6. J.S. Skyler, G.L. Bakris, E. Bonifacio, T. Darsow, R.H. Eckel, L. Groop, P.H. Groop, Y. Handelsman, R.A. Insel, C. Mathieu, A.T. McElvaine, J.P. Palmer, A. Pugliese, D.A. Schatz, J.M. Sosenko, J.P.H. Wilding, and R.E. Ratner, Diabetes, 66(2), 241(2017), DOI:10.2337/db160806

7. C.L. Triplitt and C.A. Reasner, 2011, Endocrinologic disorders, in: R.L. Talbert (Eds.), Pharmacotherapy: A Pathophysiologic Approach, The McGraw-Hill Companies Inc., pp. 12551302.

8. J. Zhong, Q. Gong, A. Goud, S. Srinivasamaharaj, and S. Rajagopalan, Journal of Diabetes Research, 12, 1(2015), DOI:10.1155/2015/606031

9. Yuliet, E.Y. Sukandar, K. Budipramana, I.K. Adnyana, Rasayan Journal of Chemistry, 13(2), 826(2020), DOI:10.31788/RJC.2020.1325607

10. C. Chen, Q. Yu, S. Zhang, P. Yang, and C.Y. Wang, International Journal of Clinical and Experimental Pathology, 8(11), 14141(2015).

11. K. Swarnalatha, C.H. Venkata Kishore Babu, and B. Hari Babu, Rasayan Journal of Chemistry, 12(2), 907(2020), DOI:10.31788/rjc.2019.1225168

12. T. Smith, M. Gillespie, V. Eckl, J. Knepper, and C.M. Reynolds, Market Report, 123 (2019).

13. S.A. Nirmal, S.C. Pal, S.O. Otimenyin, T. Aye, M. Elachouri, S.K. Kundu, R.A Thandavarayan, and S.C. Mandal, The Pharma Review, 2013.

14. H.M. Marvaniya and H.U Patel, World Journal of Pharmacy and Pharmaceutical Sciences, 6(8), 551(2017), DOI:10.20959/wjpps20178-9797

15. I. Schechter and A. Berger, Biochemical Biophysical Research Communications, 27(2), 157(1967), DOI:10.1016/s0006-291x(67)80055-x

16. S. Arulmozhiraja, N. Matsuo, E. Ishitsubo, S. Okazaki, H. Shimano, and H. Tokiwa, Plos One, 11(11), 1(2016), DOI:10.1371/journal.pone0166275

17. P. Chen, D. Feng, X. Qian, J. Apgar, R. Wilkening, J.T. Kuethe, Y.D. Gao, G. Scapin, J. Cox, G. Doss, G. Eirmann, H. He, X. Li, K.A. Lyons, J. Metzger, A. Petrov, J.K. Wu, S. Xu, A.E. Weber, Y. Yan, R.S. Roy, and T. Biftu, Bioorganic and Medicinal Chemistry Letters, 25(24), 5767(2015), DOI:10.1016/j.bmcl.2015.10.070

18. W. Lai, C. Li, J. Liu, L. Kong, X. Wen, and H. Sun, European Journal of Medicinal Chemistry, 83, 547(2014), DOI:10.1016/j.ejmech.2014.06.044

19. M. Kishimoto, Diabetes, Metabolic Syndrome and Obesity: Targets and Therapy, 6, 187(2013), DOI:10.2147/DMSO.S35682

20. M. Maladkar, S. Sankar, and K. Kamat, Journal of Diabetes Mellitus, 6(2), 113(2016), DOI: $10.4236 / \mathrm{jdm} .2016 .62012$

21. Y. Geng, Z.M Lu, W. Huang, H.Y. Xu, J.S Shi, and Z.H Xu, Molecules, 18(1), 1150(2013), DOI:10.3390/molecules 18011150

22. X. Du, Y. Li., Y.L Xia., S.M Ai, J. Liang, P. Sang, X.L Ji, and S.Q Liu, International Journal of Molecular Sciences, 17(2), 144(2016), DOI:10.3390/ijms17020144

23. F. Rivas, A. Parra, A. Martinez, and A.G. Granados, Phytochemistry Reviews, 12, 327(2013), DOI: $10.1007 / \mathrm{s} 11101-013-9301-9$

24. N. Yadav, R. Yadav, and A. Goyal, International Journal of Pharmaceutical Sciences Review and Research, 27(2), 272(2014).

25. S.D. Maryanto, R.E. Ranis, and B.S. Daryono, Journal of Proceeding Series, 1(1), 523(2014).

26. Z, Jiang, C. Kempinski, and J. Chappell, Current Protocols in Plant Biology, 1(2), 345(2016), DOI:10.1002/cppb.20024 
27. M. Huang, J.J. Lu, M.Q. Huang, J.L. Bao, X.P. Chen, and Y.T. Wang, Expert Opinion on Investigational Drugs, 21(12), 1801(2012), DOI:10.1517/13543784.2012.727395

28. V. Prakash, Asian Journal of Pharmaceutical and Clinical Research, 10(3), 68(2017), DOI:10.22159/ajpcr.2017.v10i3.16435

29. I. Jantan, W. Ahmad, and S.N.A. Bukhari, Frontiers in Plant Science, 6, 655(2015), DOI:10.3389/fpls.2015.00655

30. J. Nazaruk and M. Borzym-Kluczyk, Phytochemistry Review, 14(4), 675(2015), DOI:10.1007/s11101-014-9369-X

31. S. Zhang, W. Lu, X. L iu, Y. Dio, F. Bai, L. Wang, L. Shan, J. Huang, H. Li, and W. Zhang, Medicinal Chemistry Communications, 2(6), 471(2011), DOI:10.1039/C0MD00245C

32. S. Saleem, L. Jafri, I.U. Haq, L.C. Chang, D. Calderwood, B.D. Green, and B. Mirza, Journal of Ethnopharmacology, 156, 26(2014), DOI:10.1016/j.jep.2014.08.017

33. K. Qian, S.Y. Kim, H.Y. Hung, L. Huang, C.H. Chen, and K.H. Lee, Bioorganic \& Medicinal Chemistry Letters, 21(19), 5653(2011), DOI:10.1016/j.bmcl.2011.07.072

34. A.M. Naglah, E.A.A. El-Galil, M.A. and Al-Omar, US Patent 9969768 (2018).

[RJC-5813/2020] 